\title{
Fotokopi Merkezlerinde Uçucu Organik Bileşiklere Maruziyet
}

\author{
Gülnihal KARA*1
}

\author{
${ }^{1}$ Konya Teknik Üniversitesi, Çevre Mühendisliği Bölümü, Konya
}

Gelis tarihi: 15.01.2019 Kabul tarihi: 30.09 .2019

Öz

Fotokopi makineleri iç ortam hava kalite problemlerine yol açabilmektedir. Laboratuar ortamında test odasında yapılan çalışmalar fotokopi makinelerinin fotokopi işlemi süresince çok sayıda uçucu organik bileşiği (UOB) yaydığını göstermiştir. Bu çalışmada dört fotokopi merkezinden ve iki dış hava örneğinden alınan alan numuneleri aktif karbon tüplerinde toplanmış ve gaz kromatografisi-kütle spektrometresi kullanılarak NIOSH tarafindan geliştirilen standart metoda göre analiz edilmiştir. Fotokopi merkezi 2'de 0,52-35,90 $\mu \mathrm{g} / \mathrm{m}^{3}$ aralı̆̆ında 18 farklı uçucu organik bileşik belirlenmiştir. Maksimum konsantrasyon $77,59 \mu \mathrm{g} / \mathrm{m}^{3}$ olarak (toluen, fotokopi merkezi 3) belirlenmiş̧ir. Fotokopi merkezlerinde toplam uçucu organik bileşik maruziyeti 15,76-129,03 $\mu \mathrm{g} / \mathrm{m}^{3}$.gün aralığında tespit edilmiştir.

Anahtar Kelimeler: Uçucu organik bileşikler, Hava, İç ortam, Fotokopi merkezi, GC/MS

\section{Exposure to Volatile Organic Compounds in Photocopy Centers}

\begin{abstract}
Photocopiers have been caused indoor air quality problems. Studies conducted in the laboratory in the test chamber have indicated that several volatile organic compounds (VOCs) emitted during photocopier operation of photocopier machines. In this study, area samples from four photocopy centers and two outdoor air samples in Konya were collected in charcoal tubes and analyzed using gas chromatographymass spectrometry according to the standard method developed by NIOSH. Eighteen different VOCs were detected in photocopy center 2 and concentrations ranged from $0.52 \mu \mathrm{g} / \mathrm{m} 3$ to $35.90 \mu \mathrm{g} / \mathrm{m}^{3}$. The maximum concentration was determined as $77.59 \mu \mathrm{g} / \mathrm{m}^{3}$ (toluene, photocopy center 3 ). The daily average exposure to TVOC in photocopy centers detected from 15.76 -to $129.03 \mu \mathrm{g} / \mathrm{m}^{3}$.
\end{abstract}

Keywords: Volatile organic compounds, Air, Indoor, Photocopy center, GC/MS

*Sorumlu yazar (Corresponding author): Gülnihal KARA, gkara@selcuk.edu.tr 


\section{GíRiș}

Günümüzde kişisel bilgisayarlar, yazıcılar ve fotokopi cihazları ofislerde yaygin halde kullanılmaktadır. Elektronik ekipmanlar, ofislerde işleri kolaylaştırırken aynı zamanda iç ortam havasını da değiştirmektedir. EPA (USA Çevre Koruma Teşkilatı) ofislerde ve fotokopi merkezlerinde oluşan UOB'lerin (uçucu organik bileşiklerin) olumsuz sağlı etkileri yaratabileceğini belirtmiş ve fotokopi makineleri ve ofis ekipmanlarından yayılan emisyon profillerinin araştırılmasını önermiştir. EPA'nın kirlilik engelleme ve ofis ekipmanları üzerine hazırlamış olduğu raporda kuru-proses fotokopi makinelerinin özellikle uçucu organik bileşiklerin (UOB) önemli kaynağı olduğu belirtilmiştir [1]. Çok sayıda yapılan çalışmada lazer ve mürekkep püskürtmeli yazıcilar, kuru proses fotokopi makineleri, kişisel bilgisayarlar ve diğer ofis malzemelerinden $\mathrm{UOB}, \mathrm{CO}_{2}, \mathrm{NO}_{2}, \mathrm{NH}_{3}$ gazlarının, ozon ve partikül madde $\left(\mathrm{PM}_{10}\right.$ ve $\left.\mathrm{PM}_{2.5}\right)$ 'lerin hatta nanopartiküllerin yayıldığı tespit edilmiştir [2-6]. Özellikle kuru proses fotokopi makineleri, fotokopi merkezlerinde potansiyel UOB, ozon ve partikül madde kaynaklarıdır. $\mathrm{Bu}$ makinelerde kullanılan farklı markalı toz tonerler ve bu tonerlerin içinde bulunan organik polimerler [7] fotokopi merkezlerinde geniş aralıkta UOB'lerin tespit edilmesinin sorumlusudur [8]. $\mathrm{Bu}$ tonerler genelde stiren ve akrilatlar (\%55), pigment olarak demiroksitler (\%50) ve amorf silika (\%3)'dan oluşan reçine içerir. Baskı işlemi süresince presleme veya 1sı ile UOB'ler (bazıları toksik veya kanserojenik) kopyalama süresince veya kopyalanan kâğıt üzerinden yayılmaktadırlar $[9,10]$.

Laboratuvar ortamında test odasında Henschel ve arkadaşları [11] tarafından yapılan çalışma, kopyalama işleminde fotokopi makinelerinin içinde ısınan tonerin stiren, ksilenler, etilbenzen, asetofenon, benzaldehid ve diğer birçok benzen türevlerinin salınımına neden olduğunu göstermiştir. Leovic ve arkadaşları [12] tarafından yapılan çalışmada fotokopi cihazlarından yayılan BTEX dahil 23 UOB, Lee ve Hsu [13] tarafından yapılan çalışmada ise BTEX dahil 60 farklı UOB tespit edilmiştir. İnsan sağlığına zararlı etkileri nedeniyle halojenli organik bileşikler, UOB'ler arasında en az araştırılan ve analizi yapılan bileşik türüdür [14]. Ancak halojenli UOB'lerin özellikle klima veya merkezi havalandırma sistemleri çalışırken veya bakımları esnasında iç ortama sızdıkları bildirilmiştir [15]. Toksik kirleticilere çalışma ofislerinde uzun süre düşük konsantrasyonda maruz kalındığında dahi tehlike yaratmaktadırlar. Hatta Benzen, tetrakloretilen ve trikloroetilen gibi bazı toksik bileşikler kanser riskini artırmaktadır [16]. Fotokopi merkezlerinde yapılan çalışmalarda potansiyel sağlık etkileri nedeniyle genellikle benzen, toluen, etilbenzen, ksilenler ve stiren (BTEX) üzerine yoğunlaşılmıştır [14,17]. Benzen ve stiren sırasıyla insanlar için bilinen ve muhtemel kanserojenler olarak sınıflandırılmaktadır [18]. Yapılan çalışmalar UOB veya yarı uçucu organik bileşiklere maruziyet ile başağrısı, göz, boğaz ve burun ve ciltte kuruluk ve tahriş, hasta bina sendromu (SBS) ve bina ile ilişkili hastalık (BRI) olarak tanımlanan kronik yorgunluk belirtilerinde artış olduğunu göstermiştir [19-22]. Elango ve arkadaşları [23] fotokopi makinelerinin damar sertliği ve kardiyovasküler hastalık riskinin artmasına neden olduğunu bildirmiştir. Benzen maruziyeti ve lösemi arasında ilişki de belirlenmiştir [24]. Laboratuvar ortamında test odasında 22 farklı UOB karışımına gönüllü kişiler maruz birakıldığında göz, boğaz ve burun da tahriş hissettiklerini belirtmişlerdir [25].

$\mathrm{Bu}$ yüzden fotokopi merkezlerinde uçucu organik bileşiklerin araştırılması ve elde edilen bulgulara göre önlemlerin alınması önemlidir. Fotokopi merkezlerindeki yazıcı ve fotokopi makinelerinde oluşan kirleticilere çalışanların maruz kaldığı konsantrasyon seviyelerini belirlemek oldukça zordur. Çünkü farklı ortam şartları örneğin fotokopi merkezlerindeki hava değişim hızı (odanın hacmi, kapının açık olması), arka plan konsantrasyonu (binanın diğer kısımlarında, dış ortam havasından sızma), diğer emisyon kaynakları (diğer ofis makineleri) ve örnekleyiciye mesafe mesleki maruziyet seviyelerini etkilemektedir. Literatürde fotokopi ile ilişkili UOBs'in araştırıldığı çalışmalar genellikle test odalarında geliştirilmiştir [26-29]. Ancak test odasında yapılan çalışmalar laboratuar ortamında 
kontrollü şartlar altında yapıldığı için alansal araştırma bulguları kadar reel değildir. $\mathrm{Bu}$ çalışmada 4 farklı fotokopi merkezinden alan örnekleri ve fotokopi merkezlerinin bulunduğu lokasyonda 2 farklı dış ortam havasından alınan örnekler toplanarak 5 tanesi halojenli toplam 20 farklı uçucu organik bileşikler araştırılmıştır.

\section{MATERYAL VE METOT}

Çalışma, Konya'da Selçuk Üniversitesi kampüsü ve kent merkezin deki fotokopi merkezlerinde toplam 30 örnekleme (20 alan ve 10 diş ortam) gerçekleştirilmiştir. Fotokopi merkezlerinden biri hariç (Fotokopi merkezi 4) diğerleri araç trafiğinden uzak konumdadır. Dış ortam etkisini belirlemek amaciyla kampüs içindeki fotokopi merkezlerine eşit mesafede bir örnekleme noktası ile kent merkezindeki fotokopi merkezinin bahçesinde bir örnekleme noktası seçilmiştir. Bu çalışmada araştırılan fotokopi merkezlerinde sıradan iç ortam materyalleri betonarme zemin, boyalı betonarme tavan, boyalı betonarme duvarlar, bir fotokopi merkezi hariç sürgülü alüminyum çerçeveli cam kapılar kullanıldığı, fotokopi merkezinin kapalı alanında genellikle birkaç ahşap masa ve sandalyelerin bulunduğu gözlenmiştir. Bazı fotokopi merkezlerinde faks makineleri, renkli fotokopi makineleri ve lazer yazıcılar olmasına rağmen nadiren kullanıldığı gözlenmiştir. $\mathrm{Bu}$ nedenle, çalışmada tespit edilen kirleticilerin siyah-beyaz fotokopi makinelerinden kaynaklandığı düşünülmektedir. Uzun süre bu merkezlerde (10-12 yıl) çalışanlar, genelde fotokopi makinelerinde Polyester resin, wax, Carbon black, styrene acrylate, organik pigment, polyolefin wax, ferrite, petroleum solvent, glyceral, alkyd resin içeren toz toner kullanıldığını belirtmişlerdir. Kişisel şikâyetleri sorgulandığında çalıştıkları ortamda sürekli keskin rahatsız edici kokunun varlığını ve bundan rahatsız olduklarını, çalıştıkları ortamda bulundukları zaman zarfında burun ve boğazda yanma hissettiklerini belirtmişlerdir. Her bir fotokopi merkezinin oda boyutları, havalandırma ve giriş tipi, yaklaşık günlük kopyalama sayısı, sıcaklık ve nem değerleri dahil olmak üzere genel özellikleri Çizelge 1'de sunulmuştur.

Çizelge 1. Araştırılan fotokopi merkezlerinin fiziksel özellikleri

\begin{tabular}{|l|c|c|c|c|l|c|c|}
\hline $\begin{array}{l}\text { Fotokopi } \\
\text { merkezi }\end{array}$ & $\begin{array}{c}\text { Hacim } \\
\mathbf{( m}^{\mathbf{3}} \mathbf{)}\end{array}$ & $\begin{array}{c}\text { Fotokopi } \\
\text { makinesi sayısı }\end{array}$ & $\begin{array}{c}\text { Kopyalama } \\
\text { sayısı }\end{array}$ & $\begin{array}{l}\text { Giriş } \\
\text { Tipi }\end{array}$ & $\begin{array}{l}\text { Dış ortam kirletici } \\
\text { kaynağı }\end{array}$ & $\begin{array}{c}\text { Sıcaklık } \\
\left.\mathbf{(}^{\mathbf{0}} \mathbf{C}\right)^{\mathbf{c}}\end{array}$ & $\begin{array}{c}\text { Nem } \\
\mathbf{( \% )}^{\mathbf{d}}\end{array}$ \\
\hline $\begin{array}{l}\text { Fotokopi } \\
\text { merkezi (1) }\end{array}$ & 175 & 5 & 8000 & A & $\begin{array}{l}\text { Kampüs içinde } \\
\text { (yoldan uzak) }\end{array}$ & 24,5 & 21 \\
\hline $\begin{array}{l}\text { Fotokopi } \\
\text { merkezi (2) }\end{array}$ & 225 & 4 & 6000 & B & $\begin{array}{l}\text { Kampüs içinde } \\
\text { (yoldan uzak) }\end{array}$ & 24,7 & 20 \\
\hline $\begin{array}{l}\text { Fotokopi } \\
\text { merkezi (3) }\end{array}$ & 100 & 3 & 8000 & B & $\begin{array}{l}\text { Kampüs içinde } \\
\text { (Orta derece trafik) }\end{array}$ & 24,5 & 20 \\
\hline $\begin{array}{l}\text { Fotokopi } \\
\text { merkezi (4) }\end{array}$ & 225 & 3 & 5000 & A & $\begin{array}{l}\text { Kent merkezi } \\
\text { (Ağır trafik) }\end{array}$ & 16,6 & 24 \\
\hline
\end{tabular}

A: Tam açık, B: Yarım açık c: Ort. 8 saat'lik sıcaklık, d: Ort. 8 saat'lik nem

Fotokopi merkezlerinden (4) hariç diğerlerinde havalandırma sistemi mevcut değildi. Bağıl nem ve sicaklık, her bir kopya merkezinde dijital psikrometre ve termometre kullanılarak ölçülmüştür. Hava örnekleri düşük akışıı SKC 224-PCTX8KV hava örnekleyicisi ile sertifikalı SKC aktif karbon tüpü (coconut shell charcoal, $100 \mathrm{mg} / 50 \mathrm{mg}$ ) kullanılarak NIOSH tarafindan geliştirilen Metot 1501'e [30] göre alınmıştır. Hava örnekleri yer seviyesinden yaklaşık 1,5 m yukardan $100 \mathrm{ml} /$ dak akış hızı ile 09:00-17:00 zaman diliminde 8 saat süre ile toplanmıştır. Akış hızı, her örneklemeden önce ve sonra SKC akış ölçer ile kontrol edilmiş ve akış hızındaki varyasyon $\% 5$ 'den düşük olarak tespit edilmiştir. Örnekleme işleminden sonra tüpler özel plastik kapaklarla kapatılmış ve plastik çanta içinde soğutucu kaplarla laboratuara getirilmiştir. Analize kadar $-101{ }^{\circ} C^{\prime}$ de derin dondurucuda korunmuştur. Örnekleme süresince konsantrasyon değişimleri 5 
blank tüp ile kontrol edilmiştir. Bilinen konsnatrasyonda VOCs standardı aktif karbon tüplerine spike yapılmış ve metot geri kazanım değerleri \%75-98 aralığında belirlenmiştir. Desorbsiyon işleminden önce aktif karbon tüplerine p-bromoflorobenzen surrogate standard 1 spike yapılmış ve geri kazanım etkinliği belirlenmiştir.

Aktif karbon tüpünün arka bölümünde ölçülen UOB'ler, toplam konsantrasyonun $\% 5$ 'inden az olarak tespit edilmiş, hedef bileşiklerin örnekleme şartlarında breakthrough olmadığı düşünülmüştür. Örneklerin tamamında her iki bölümde analiz edilmiştir. NIOSH Metot 1501 'de belirtilen yönteme göre distile karbondisülfid kullanılarak desorbsiyon işlemi gerçekleştirilmiş, solvent faz Chromafil O-45/25 şırınga filtreden geçirilerek
5973 seri MS dedektör ve DB-5 kolon ile donatılmış Agilent $6890 \mathrm{~N}$ gaz kromatografisine enjekte edilmiştir. UOBs'in GC-MS sistemi için LOD ve LOQ değerleri $1 \mathrm{ng} / \mu \mathrm{L}$ konsantrasyonundaki standart çözeltinin optimum GC-MS şartlarındaki enjeksiyonu sonucunda elde edilen her bileşiğe ait $\mathrm{S} / \mathrm{N}$ oranı değerleri kullanılarak hesaplanmıştır. LOD (Dedeksiyon limiti), LOQ (Kantifikasyon limiti), lineer aralık, lineerlik $\left(\mathrm{R}^{2}\right)$, RSD (Relatif standart sapma) olarak tekrarlanabilirlik, Doğruluk PSN değerleri Çizelge 2'de verilmiştir. 1-klorooktan ve 1-klorooktadekan'dan oluşan internal mix enjeksiyon kontrol standardı olarak kullanılmıştır.

Dış ortam ve fotokopi merkezlerindeki alan örnekleme sonuçları Çizelge 3'de sunulmuştur.

Çizelge 2. UOB'ler için GC-MS sistemi ile elde edilen LOD, LOQ, lineer aralık, PSN, R², \%RSD değerleri

\begin{tabular}{|c|c|c|c|c|c|c|}
\hline \multirow{3}{*}{ Bileşikler } & \multicolumn{6}{|c|}{ GC-MS } \\
\hline & LOD & LOQ & \multirow{2}{*}{$\begin{array}{l}\text { Lineer Aralık } \\
n g \mu \mathrm{L}^{-1}\end{array}$} & \multirow{2}{*}{ PSN (\%) } & \multirow{2}{*}{$\mathrm{R}^{2}$} & \multirow{2}{*}{ RSD } \\
\hline & \multicolumn{2}{|c|}{$\mathrm{ng} \mathrm{m}^{-3}$} & & & & \\
\hline Benzen & 1,567 & 5,218 & $0,001-10$ & 98 & 0,990 & 1,299 \\
\hline Toluen & 1,675 & 5,577 & $0,001-10$ & 99 & 0,996 & 2,605 \\
\hline 1,2 Dibromoetan & 15,879 & 52,877 & $1-10$ & 100 & 0,999 & 7,792 \\
\hline Etilbenzen & 1,681 & 5,597 & $0,001-10$ & 96 & 0,997 & 2,605 \\
\hline $\mathrm{m} / \mathrm{p}$ Ksilen & 0,439 & 1,461 & $0,001-10$ & 96 & 1,000 & 4,895 \\
\hline Stiren & 3,215 & 10,705 & $0,01-10$ & 100 & 0,998 & 7,415 \\
\hline o-ksilen & 1,006 & 3,349 & $0,001-10$ & 99 & 1,000 & 2,792 \\
\hline İsopropilbenzen & 2,432 & 8,098 & $0,01-10$ & 100 & 0,999 & 2,177 \\
\hline bromobenzen & 2,235 & 7,451 & $0,01-10$ & 100 & 1,000 & 5,181 \\
\hline npropilbenzen & 2,635 & 8,774 & $0,01-10$ & 100 & 0,999 & 3,447 \\
\hline m-p etil toluen & 1,687 & 5,617 & $0,001-10$ & 100 & 0,999 & 5,030 \\
\hline o-etiltoluen & 2,569 & 8,562 & $0,01-10$ & 96 & 0,998 & 4,012 \\
\hline 1,3,5 Trimetilbenzen & 1,689 & 5,629 & $0,001-10$ & 100 & 1,000 & 1,561 \\
\hline 1,2,4 Trimetilbenzen & 1,670 & 5,566 & $0,001-10$ & 100 & 1,000 & 1,761 \\
\hline 1,3 Diklorobenzen & 2,456 & 8,178 & $0,01-10$ & 100 & 0,998 & 2,215 \\
\hline 1,4 Diklorobenzen & 2,460 & 8,191 & $0,01-10$ & 100 & 0,996 & 2,341 \\
\hline 1,2,3 Trimetilbenzen & 2,026 & 6,753 & $0,01-10$ & 100 & 1,000 & 2,214 \\
\hline 1,2 Diklorobenzen & 2,512 & 8,364 & $0,01-10$ & 100 & 0,996 & 2,612 \\
\hline 1,2 Dibromo (3) kloropropan & 18,712 & 62,310 & $1-10$ & 96 & 0,996 & 17,36 \\
\hline 1,2,4 Triklorobenzen & 2,712 & 9,03 & $0,01-10$ & 100 & 0,998 & 3,190 \\
\hline S1 -p-Bromoflorobenzen & 15,870 & 52,899 & $0,01-10$ & 98 & 0,996 & 4,450 \\
\hline Internal-1 1-klorooktan & 2,844 & 9,479 & $0,001-10$ & 100 & - & - \\
\hline Intemal-2 1-klorooktadekan & 1,048 & 3,495 & $0,001-10$ & 100 & - & - \\
\hline
\end{tabular}




\section{TARTIŞMA VE SONUÇLAR}

Dış ortam ve fotokopi merkezlerinde ve alan örneklerinde tespit edilen UOBs'in konsantrasyonları arazi blank değerlerine göre düzeltilmiştir. Arazi blanklerinde çok düşük miktarlarda benzen, etilbenzen, stiren ve toluen, 1,2,4 trimetilbenzen ve 1,2 Dibromo (3) kloropropan belirlenmiştir. 5 arazi blank tüpünde tespit edilen UOBs'in konsantrasyon değerleri LOD’den düşük olarak belirlenmiştir.

Diş ortam ve fotokopi merkezlerindeki alan örnekleme sonuçları Çizelge 2'de sunulmuştur. Çizelge 3'de LOD değerinden küçük konsantrasyonlar <LOD olarak ifade edilmiştir. Çalışmada benzen, toluen, ksilen, isopropilbenzen, 1,2,4 Trimetilbenzen ve $\mathrm{m}+\mathrm{p}$ Etiltoluen ve stiren fotokopi merkezlerinde en baskın bileşik grupları olmuştur. Laboratuvar ortamında test odasında yapılan çalışmalar benzen, toluen, ksilenler, diğer benzen bileşikleri, alifatik hidrokarbonlar, aldehit ve esterlerin ofis makinelerinden kaynaklanan bileşikler arasında en sik tespit edilen grup olduğunu göstermiştir [31,32]. Çalışmada en yüksek konsantrasyonda tespit edilen bileşik toluen $\left(77,59 \mu \mathrm{g} / \mathrm{m}^{3}\right.$, fotokopi merkezi 3)'dir. $\mathrm{Bu}$ bileşiğin fotokopi makinelerinde kullanılan toner, ciltleme işlemindeki yapıştırıcı ve temizleme solventlerinden kaynaklandığı düşünülmüştür [33]. Özellikle stiren dış ortam örneklemelerinde tespit edilmemiş ancak fotokopi merkezlerinin tamamında tespit edilmiştir. Bu bileşiğin fotokopi işlemi süresince kullanılan boya ve solventlerden kaynaklandığı düşünülmektedir [34]. Araştırılan 5 tane halojenli uçucu halojenli organik bileşiklerden 1,2 Dibromoetan bir fotokopi merkezinde (Fotokopi merkezi (1)), 1,2,4 Triklorobenzen iki fotokopi merkezinde (Fotokopi merkezi (2) ve Fotokopi merkezi (3)), bromobenzen bir fotokopi merkezinde (Fotokopi merkezi (2)), 1,2 Diklorobenzen ve 1,2 Dibromo (3) kloropropan bir fotokopi merkezinde (Fotokopi merkezi (2)) belirlenmiştir. Ongwandee ve arkadaşları [19] tarafindan Bangkok'da 17 klimalı ofis binasında 5 tanesi klorlu (tetrakloroeten, trikloroeten, 1,2 dikloroetan, 1,2 dikloropropan ve kloroform) toplam 13 UOB'i araştırdıkları çalışmada ofis havasındaki klorlu organik bileşik emisyonlarının kuru temizlenmiş kıyafetlerden, halı, mobilya temizleme kimyasalları ve diğer solvent kullanımlarından kaynaklandığını belirtmişlerdir. $\mathrm{Bu}$ çalışmada tespit edilen halojenli UOBs'in yapıştırıcı ve temizleme kimyasallarından kaynaklandığı ve kullanıldıkları zaman diliminde iç ortam havalandırmasına dikkat edilmesi gerektiği düşünülmüştür.

Dış ortam havasının iç ortam havasına etkisini belirlemek amacıyla yapılan 2 dış ortam örnekleme sonuçları incelendiğinde en yüksek konsantrasyonda tespit edilen bileşik kent merkezinde toluen $\left(29,81 \mu \mathrm{g} / \mathrm{m}^{3}\right)$ olmuştur. Konya kent merkezinde UOBs' in konsantrasyonu kampüs bölgesine göre yaklaşık 3 kat daha yüksek belirlenmiştir. Kent merkezinde ve kampüs bölgesindeki dış ortam örneklemeleri incelendiğinde kent merkezinde etilbenzen, ksilen ve toluen seviyelerinde önemli artış gözlenmiştir. Bunun nedeninin ksilenlerin benzin katkı maddesi olarak kullanılıyor olması olarak düşünülmüştür [35]. Benzen, etilbenzen ve toluen kentsel cadde kanyonlarında otomobil emisyonlarının göstergesidir [36]. Bu durum kent merkezin deki yoğun trafiğin kirletici emisyonları arttırdığını göstermektedir. Fotokopi merkezi 4'te tespit edilen yüksek UOBs seviyelerine dış ortamın katkı sağladığ1 düşünülmüştür. Kampüs bölgesinde fotokopi merkezi 3'te kent merkezinden dahi yüksek UOBs seviyeleri belirlenmiştir. $\mathrm{Bu}$ fotokopi merkezi orta derece trafiğe yakın oda hacmi çok küçük (100 m3), fotokopi makine sayısı az ancak kopyalama sayısı en yüksek merkezlerden biridir. $\mathrm{Bu}$ fotokopi merkezinde tespit edilen yüksek UOBs seviyeleri dış ortam etkisinden ziyade fotokopi makinelerinin yaymış olduğu emisyonların yüzünden olduğu düşünülmüştür. UOBs, insan sağlığına zararlı etkilerinin yanı sıra ozon ve nanopartikül gibi yeni kirleticilerin oluşumuna katkı sağlamaları ile araştırılması gerekli bileşik grubudur. Fotokopi merkezlerinin iç ortam hava kalitesi ile ilgili sınırlı sayıda çalışma olması, konu ile ilgili yasal prosedürleri de etkilemektedir. Ülkemizdeki Yönetmeliklerde fotokopi merkezlerindeki iç ortam hava kalitesi ile ilgili kriterlerin henüz düzenlenmemiş olması önemli eksikliklerden 
biridir. $\mathrm{Bu}$ nedenle, fotokopi işlemi sırasında yayılan kirleticiler öngörülen seviyelerden daha yüksek olabilir ve çalışanlar üzerinde potansiyel olarak olumsuz sağlık etkileri yaratabilir. Fotokopi merkezlerinde çalışan işçilerin maruz kaldıkları riski minimize etmek için önlemler alınmalıdır. $\mathrm{Bu}$ önlemler, daha düşük emisyon yayan ekipmanların tercih edilmesi örneğin kuru proses fotokopi makineleri yerine rslak proses tercih edilmesi, fotokopi makinelerinde ozon filtrelerinin mutlaka olması ve düzenli aralıklarla değiştirilmesi, fotokopi makinelerinin egzozunun çalışanları ve müşterileri en az etkileyecek konuma yerleştirilmesi, makinelerin bulunduğu odanın havalandırılmasının sağlanması ve son olarak kuru proses makinelerin toz tonerinin tekrar doldurulması esnasında çevreye dökülmesinin engellenmesidir. Fotokopi işlemi süresince çok farklı türde kirletici grubu oluşmaktadır. Bunlardan bazı kirletici grupları ile ilgili sınırlı sayıda dahi olsa çalışma varken henüz hiç araştırılmayan fotokopi makinelerinde isıya dayanıklı yağlayıcı olarak kullanılan silikon yağı veya silikon gresinden oluşan teknik karışımların neden olduğu polisiloksanlar [37] gibi kirletici grupları da araştırılmalıdır.

Çizelge 3. Fotokopi merkezlerinde ve dış ortam havasında ölçülen UOBs'in alan örnekleme sonuçları $\left(\mu \mathrm{g} / \mathrm{m}^{3}\right)$

\begin{tabular}{|c|c|c|c|c|c|c|c|c|c|c|c|c|c|c|c|c|c|c|}
\hline & \multicolumn{3}{|c|}{ Fotokopi Merkezi 1} & \multicolumn{3}{|c|}{ Fotokopi Merkezi 2} & \multicolumn{3}{|c|}{ Fotokopi Merkezi 3} & \multicolumn{3}{|c|}{ Fotokopi Merkezi 4} & \multicolumn{3}{|c|}{ Dış ortam (Kırsal) } & \multicolumn{3}{|c|}{$\begin{array}{c}\text { Diş ortam (Kent } \\
\text { merkezi-yoğun trafik) }\end{array}$} \\
\hline & & Ort. & $\mathrm{S}$ & & Ort. & S & & Ort. & $\mathrm{S}$ & & Ort. & $\mathrm{S}$ & & Ort. & $\mathrm{S}$ & & Ort. & $\mathrm{S}$ \\
\hline Bileşikler & Mak. & $(\mathrm{n}=5)$ & & Mak. & $(n=5)$ & & Mak. & $(\mathrm{n}=5)$ & & Mak. & & & Mak. & $(n=5)$ & & Mak. & $(n=5)$ & \\
\hline Benzen & 4,07 & 3,67 & 0,40 & 0,52 & 0,52 & 0,01 & 5,64 & 4,91 & 0,73 & 27,50 & 24,03 & 3,48 & 1,57 & 1,29 & 2,74 & 2,400 & 2,238 & 1,62 \\
\hline Toluen & 8,81 & 8,36 & 0,45 & 35,90 & 34,30 & 1,60 & 77,59 & 73,86 & 3,73 & 47,64 & 41,58 & 6,06 & 7,96 & 6,57 & 5,23 & 29,81 & 18,06 & 4,26 \\
\hline 1,2 Dibromoetan & 0,88 & 0,64 & 0,23 & $<$ LOD & $<\mathrm{LOD}$ & & $<\mathrm{LOD}$ & $<\mathrm{LOD}$ & & 0,81 & 0,41 & 0,40 & $<\mathrm{LOD}$ & $<$ LOD & & 0,07 & 0,03 & 0,03 \\
\hline Etilbenzen & 0,52 & 0,48 & 0,04 & 0,61 & 0,56 & 0,06 & 6,12 & 5,61 & 0,51 & 1,02 & 1,01 & 0,01 & 0,70 & 0,61 & 0,10 & 2,00 & 1,95 & 0,04 \\
\hline m-p Ksilen & 1,06 & 0,91 & 0,15 & 1,23 & 1,21 & 0,01 & 19,10 & 18,23 & 0,88 & 4,76 & 4,63 & 0,03 & 0,90 & 0,85 & 0,05 & 4,19 & 3,65 & 0,53 \\
\hline Stiren & 0,49 & 0,44 & 0,06 & 1,25 & 1,23 & 0,02 & $<\mathrm{LOD}$ & $<\mathrm{LOD}$ & & 1,14 & 1,07 & 0,07 & $<\mathrm{LOD}$ & $<$ LOD & & 0,36 & 0,26 & 0,30 \\
\hline o-Ksilen & $<$ LOD & $<\mathrm{LOD}$ & & \begin{tabular}{|l|}
11,11 \\
\end{tabular} & 6,45 & 4,66 & 6,20 & 5,77 & 0,43 & $<$ LOD & $<\mathrm{LOD}$ & & 0,90 & 0,88 & 0,02 & 2,31 & 2,1 & 0,10 \\
\hline İsopropilbenzen & $<\mathrm{LOD}$ & $<\mathrm{LOD}$ & & 4,34 & 2,17 & 2,17 & $<\mathrm{LOD}$ & $<\mathrm{LOD}$ & & 0,85 & 0,80 & 0,05 & $<\mathrm{LOD}$ & $<$ LOD & & $<\mathrm{LOD}$ & $\angle \mathrm{LOD}$ & \\
\hline Bromobenzen & $<$ LOD & $<\mathrm{LOD}$ & & 20,45 & 11,04 & 4,41 & $<\mathrm{LOD}$ & $<\mathrm{LOD}$ & & $<$ LOD & $<\mathrm{LOD}$ & & $<\mathrm{LOD}$ & $<$ LOD & & $<\mathrm{LOD}$ & $<\mathrm{LOD}$ & \\
\hline n-propilbenzen & $<\mathrm{LOD}$ & $<\mathrm{LOD}$ & & \begin{tabular}{|l|}
5,37 \\
\end{tabular} & 3,61 & 1,76 & \begin{tabular}{|l|}
0,95 \\
\end{tabular} & \begin{tabular}{|l|}
0,93 \\
\end{tabular} & 0,02 & $<\mathrm{LOD}$ & $<\mathrm{LOD}$ & & 0,10 & \begin{tabular}{|l|}
0,10 \\
\end{tabular} & & $<\mathrm{LOD}$ & $\angle \mathrm{LOD}$ & \\
\hline $\mathrm{m}+\mathrm{p}$ Etiltoluen & $<$ LOD & $<\mathrm{LOD}$ & & 8,38 & 6,65 & 1,72 & 2,73 & 2,52 & 0,21 & $<\mathrm{LOD}$ & $<\mathrm{LOD}$ & & $<\mathrm{LOD}$ & $<$ LOD & & 5,47 & 5,28 & 0,18 \\
\hline O-etiltoluen & $<$ LOD & $<$ LOD & & 4,66 & 3,66 & 1,01 & 6,10 & 6,03 & 0,07 & $<$ LOD & $<$ LOD & & $<\mathrm{LOD}$ & $<$ LOD & & $<\mathrm{LOD}$ & $<\mathrm{LOD}$ & \\
\hline 1,3,5 Trimetilbenzen & $<$ LOD & $<\mathrm{LOD}$ & & 8,90 & 6,44 & 2,46 & $<\mathrm{LOD}$ & $<\mathrm{LOD}$ & & $<\mathrm{LOD}$ & $<\mathrm{LOD}$ & & $<\mathrm{LOD}$ & $<$ LOD & & $<\mathrm{LOD}$ & $<\mathrm{LOD}$ & \\
\hline 1,2,4Trimetilbenzen & 1,50 & 1,26 & 0,25 & 26,50 & 21,71 & 4,79 & $<\mathrm{LOD}$ & $<\mathrm{LOD}$ & & $<\mathrm{LOD}$ & $<\mathrm{LOD}$ & & 0,81 & 0,58 & 0,23 & $<\mathrm{LOD}$ & $<\mathrm{LOD}$ & \\
\hline 1,3 Diklorobenzen & $<\mathrm{LOD}$ & $<\mathrm{LOD}$ & & $<\mathrm{LOD}$ & $<\mathrm{LOD}$ & & $<$ LOD & $<\mathrm{LOD}$ & & $<$ LOD & $<\mathrm{LOD}$ & & $<\mathrm{LOD}$ & $<\mathrm{LOD}$ & & $<\mathrm{LOD}$ & $\angle \mathrm{LOD}$ & \\
\hline 1,4 Diklorobenzen & $<$ LOD & $<$ LOD & & $<\mathrm{LOD}$ & $<\mathrm{LOD}$ & & $<$ LOD & $<\mathrm{LOD}$ & & $<$ LOD & $<\mathrm{LOD}$ & & $<\mathrm{LOD}$ & $<$ LOD & & $<\mathrm{LOD}$ & $\angle \mathrm{LOD}$ & \\
\hline 1,2,3 Trimetilbenzen & $<\mathrm{LOD}$ & $<\mathrm{LOD}$ & & \begin{tabular}{|l|}
15,71 \\
\end{tabular} & 7,86 & 7,86 & $<\mathrm{LOD}$ & $<\mathrm{LOD}$ & & $<\mathrm{LOD}$ & $<\mathrm{LOD}$ & & $<\mathrm{LOD}$ & $<$ LOD & & $<\mathrm{LOD}$ & $<\mathrm{LOD}$ & \\
\hline 1,2 Diklorobenzen & $<\mathrm{LOD}$ & $<\mathrm{LOD}$ & & 16,85 & 8,42 & 8,42 & $<\mathrm{LOD}$ & $<\mathrm{LOD}$ & & $<\mathrm{LOD}$ & $<\mathrm{LOD}$ & & $<\mathrm{LOD}$ & $<\mathrm{LOD}$ & & $<\mathrm{LOD}$ & $\angle \mathrm{LOD}$ & \\
\hline $\begin{array}{l}\text { 1,2 Dibromo(3) } \\
\text { kloropropan }\end{array}$ & $<\mathrm{LOD}$ & $<\mathrm{LOD}$ & & 15,01 & 7,50 & 7,50 & $<\mathrm{LOD}$ & $<\mathrm{LOD}$ & & $<\mathrm{LOD}$ & $<$ LOD & & 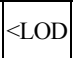 & LOD & & & $<\mathrm{LOD}$ & \\
\hline 1,2,4 Triklorobenzen & $<\mathrm{LOD}$ & $<\mathrm{LOD}$ & & 11,44 & 5,72 & 5,72 & \begin{tabular}{|l|}
19,98 \\
\end{tabular} & 9,99 & 0,73 & $<\mathrm{LOD}$ & $<\mathrm{LOD}$ & & $<\mathrm{LOD}$ & $\mid<$ LOD & & $<\mathrm{LOD}$ & $\mid<\mathrm{LOD}$ & \\
\hline
\end{tabular}

S: Standart sapma, Ort.: 8 saatlik ortalama konsantrasyon, Mak.: Maksimum konsantrasyon

\section{KAYNAKLAR}

1. US EPA, 1991. Building Air Quality: A Guide for Building Owners and Managers, EPA/400/1-91/033, Washington.

2. Khatri M., Bello D., Pal A., Joel MC., Woskie S., Gassert T., Lan J., Gu AZ., Demokritou P., Gaines P., 2013. Evaluation of Cytotoxic, Genotoxic and Inflammatory Responses of Nanoparticles from Nphotocopiers in Three Human Cell Lines, Part. Fibre Toxicol, 10, 42-64.
3. Martin J., Bello D., Bunker K., Shafer M., Christiani D., Woskie S., Demokritou P., 2015. Occupational Exposure to Nanoparticles at Commercial Photocopy Centers, J Hazard Mater, 298, 351-360.

4. He C., Morawska L., Taplin L., 2007. Particle Emission Characteristics of Office Printers. Environ Sci Technol, 4, 6039-6045.

5. Kiurski, J.S., Marić, B.B., Oros, I.B., Kecić, V.S., 2017. The Ecodesign Practice in Serbian Printing Industry, J Clean Prod, 149, 1200-1209. 
6. Tang T., Hurra J., Gminski R., MerschSundermann V., 2012. Fine and Ultrafine Particles Emitted from Laser Printers as Indoor Air Contaminants in German offices, Environ Sci Pollut Res Int, 19(9), 3840-3849.

7. Kim SY., Kim Y., Byeon JH., Lee DY., Hwang J., 2009. Emission of Submicron Aerosol Particles in Operating a Laser Beam Printer. Int J Precis Eng Manuf, 10(5), 33-36.

8. Destaillats H., Maddalena RL., Singer BC., Hodgson AT., McKone TE., 2008. Indoor Pollutants Emitted by Office Equipment: a Review of Reported Data and Information Needs, Atmos Environ, 42, 1371-1388.

9. Kowalska, J., Szewczyńska, M., Pośniak, M., 2015. Measurements of Chlorinated Volatile Organic Compounds Emitted from Office Printers and Photocopiers, Environ Sci Pollut Res, 22, 5241-5252.

10. Kiurski, JS., Aksentijević, S.M., Mandarić, S.D., 2018. Statistical Approach for Characterization of Photocopying Indoor Pollution, Air Qual Atmos Health, 11, 867-881.

11. Henschel, B.D., Fortann, R.C., Roache, N.F., 2001. Variations in the Emission of Volatile Organic Compounds from the Toner for a Specific Photocopier, J Air Waste Manag Assoc, 51, 708-717.

12. Leovic, K.W., Whitaker, D.A., Northeim, C., Sheldon, L.S., 1996. Measurement of Indoor Air Emissions from Dry-process Photocopy Machines, J Air Waste Manag Assoc, 46, 821-829.

13. Lee, C.W., Hsu, D.J., 2007. Measurements of Fine and Ultrafine Particles Formation in Photocopy Centers in Taiwan, Atmos Environ, 41, 6598-6609.

14. Lee, S.C., Lam, S., Fai. H.K., 2001. Characterization of VOCs, Ozone and PM10 Emissions from Office Equipment in an Environmental Chamber, Build Environ, 36, 837-842.

15. Awadi, L.A., Rashidi, M.A., Pereira, B., Pillai, A., Khan, A., 2018. Indoor Air Quality in Printing Press in Kuwait, Int $\mathrm{J}$ Environ Sci Technol, 10(1007), 1-14.

16. Salonen, H., Pasanen, A.L., Lappalainen, S., Riuttala, H., Tuomi, T., Pasanen, P., Bäck, B., Reijula, K., 2009. Volatile Organic
Compounds and Formaldehyde as Explaining Factors for Sensory İrritation in Office, J. Occup. Environ. Hyg; 6, 239-247.

17. Leovic, K.W., Whitaker, D.A., Northeim, C., Sheldon, L.S., 1998. Evaluation of Test Method for Measuring Indoor Air Emissions from Dry-process Photocopiers, J. Air Waste Manag. Assoc; 48, 915-923.

18. IARC (International Agency for Research on Cancer) 2004. Overall Evaluations of Carcinogenicity to Humans as Evaluated in IARC Monographs Volumes 1-82 (a total of 885 agents, mixtures and exposures).

19. Ongwandee, M., Moonrinta, R., Panyametheekul, S., Tangbanluekal, C.H., Morrison, G., 2011. Investigation of Volatile Organic Compounds in Office Buildings in Bangkok, Thailand: Concentrations, Sources, and Occupant Symptoms, Build Environ, 46, 1512-1522.

20.Kuo, Y.M., Chiu, C.H., Yu, H.L., 2015. Influences of Ambient Air Pollutants and Meteorological Conditions on Ozone Variations in Kaohsiung, Taiwan, Stoch Environ Res Risk Assess, 29, 1037-1050.

21. Vicente, E.D., Ribeiro, J.P., Custódio, D., Alves, C.A., 2017. Assessment of the Indoor Air Quality in Copy Centres at Aveiro, Portugal, Air Qual Atmos Health, 10, 117-127.

22. Wolkoff, P., Wilkins, C.K., Clausen, P.A., Nielsen, G.D., 2006a. Organic Compounds in Office Environments-sensory Irritation, Odor, Measurements and the Role of Reactive Chemistry, Indoor Air, 16, 7-19.

23. Elango, N., Kasi, V., Vembhu, B., Poornima, JG., 2013. Chronic Exposure to Emissions from Photocopiers in Copy Shops Causes Oxidative Stres and Systematic Inflammation Among Photocopier Operators in India, Environ Health, 12(78), 1-12.

24. Pattinson, W., Targino, AC., Gibson, MD., Krecl, P., Cipoli, Y., Sá, V., 2018. Quantifying Variation in Occupational Air Pollution Exposure Within a Small Metropolitan Region of Brazil, Atmos Environ, 182, 138-154.

25. Koren, H.S., Graham, D.E., Devlin, R.B., 1992. Exposure of Humans to a Volatile Organic Mixture. III. Infammatory Response. Arch. Environ. Health, 47, 39-44. 
26. Serfozo, N., Ondráček, J., Glytsos, T., Lazaridis, M., 2018. Evaluation of Nanoparticle Emissions from a Laser Printer in an Experimental Chamber and Estimation of the Human Particle Dose, Environ. Sci. Pollut. Res. 25, 13103-13117.

27. Hsu, D.J., Huang, H.L., Chien, C.H., Lin, T.S., 2005. Potential Exposure to VOCs Caused by Dry Process Photocopiers: Results from a Chamber Study, Bull Environ Contam Toxicol $75,1150-1155$.

28. Hsu, D.J., Huang, H.L., Lin, H.Y., Lin, Lin, T.S., 2006. Potential Volatile Organic Compound Exposure from Dry Process Photocopiers in Operation-idle Mode, Bull. Environ. Contam. Toxicol. 76, 922-929.

29. Lee, C.W., Dai, Y.T., Chien, C.H., Hsu, D.J., 2006. Characteristics and Health Impacts of Volatile Organic Compounds in Photocopy Centers, Environ. Res. 100, 139-49.

30. NIOSH, 2007. NIOSH Manual of Analytical Methods No. 1501: Hydrocarbons, Aromatic, 2003.

31. Kagi, N., Fujii, S., Horiba, Y., Namiki, N., Ohtani, Y., Emi, H., Tamura, H., Kim, Y.S., 2007. Indoor Air Quality for Chemical and Ultrafine Particle Contaminants from Printers, Build. Environ. 42, 1949-1954.

32. Wang, Z.M., Wagner, J., Wall, S., 2011. Characterization of Laser Printer Nanoparticle and VOC Emissions, Formation Mechanisms, and Strategiesmto Reduce Airborne Exposures, Aerosol Sci. Tech. 45, 1060-1068.

33. Senthong, P., Wittayasilp, S., 2018. Measurements and Health Impacts of Carbon Black and BTEXs in Photocopy Centers, Arch. Environ. Occup. Health. 73(3), 169-175.

34. Sarkhosh, M., Mahvi, A.H., Zare, M.R.,, Fakhri Y., Shamsolahi HR., 2012. Indoor Contaminants from Hardcopy Devices: Characteristics of VOCs in Photocopy Centers, Atmos. Environ. 63, 307-312.

35. ATSDR 2004. (Agency for Toxic Substances and Disease Registry) (ATSDR), http://www. atsdr.cdc.gov/.

36. Zhao, L., Wang, XM., He, Q., Wang, H., Sheng, G.Y., Chan, L.Y., Fu, J.M., Blake, D.R., 2004. Exposure to Hazardous Volatile Organic Compounds, PM10 and CO While
Walking Along Streets in Urban Guangzhou, China, Atmos. Environ. 38, 6177-6184.

37. Salthammer, T., Schripp, T., Uhde, E., Wensing, M., 2012. Aerosols Generated by Hardcopy Devices and Other Electrical Appliances. Environ. Pollut. 169, 167-174. 